\title{
The Impact of the Greek Economic Crisis on the Greek Construction Companies. Back to Basics: tHe Statistical Cost Accounting Model
}

\author{
${ }^{1}$ Eriotis Nikolaos, ${ }^{2}$ Kalantonis Petros, \\ ${ }^{3}$ Papadopoulou Eleni, ${ }^{4}$ Poutos Evangelos and ${ }^{5}$ Vasiliou Dimitrios \\ ${ }^{1,4}$ National and Kapodistrian University of Athens, Greece \\ ${ }^{2}$ Department of Business Administration, TEI of Piraeus \\ ${ }^{3}$ Financial Analyst/Modeller, London, UK \\ ${ }^{5}$ Hellenic Open University, Patra, Greece
}

Received 2014-02-07; Revised 2014-06-05; Accepted 2014-06-24

\begin{abstract}
This study applies to the statistical cost accounting model to capture the impact of the Greek economic crisis on the returns of the Greek construction sector using the published financial statements of the construction firms listed on the Athens Exchange during 2005-2011. The evidence from our analysis suggests that the construction sector has been affected by the Greek crisis since there is a great decrease of the construction activities. According to our results, our findings support the theoretical model and reveals that there is a negative impact on the earnings due to the underemployment of the fixed assets. Additionally, we find that the cash and cash equivalent items do not actually help our sample firms to produce profit and the most expensive item of the balance sheet is the non financial short term liabilities.
\end{abstract}

Keywords: Construction Sector, Liabilities, Operating Income

\section{INTRODUCTION}

In an uncertain economic environment, where everything is reconsidered and reconstructed, there are massive losses by the existing companies and some great opportunities for those, which either will manage to survive or invest just after the trough stage of the economy. Following the global financial crisis and the lack of confidence in the global financial system (De Grauwe, 2010) the problem focused to the most weaken countries, such as Greece (Hardouvelis, 2011). The Greek economic crisis, which started as a financing problem, revealed the country's inadequacy to produce surplus. As a result the economic activity in Greece felt sharply. In numbers (BOG, 2012), the Greek GDP changed from $+4.6 \%$ n 2008 to $-0.5 \%$ in $2009,-1.9 \%$ in $2010,-5.4 \%$ in 2011 and is expected to be at $-5.4 \%$ at the end of 2012. Additionally, the deficit as a percentage of GDP had the value of $-6.3 \%$ in 2008 , doubled in 2009 and it is expected to be- $6.9 \%$ by the end of 2012 . These facts had a negative result on the Greek consolidated debt, which has been increased from $107.5 \%$ of GDP in 2007 to $165.3 \%$ in 2011 (For an extensive research see Kouretas and Vlamis, 2010).

The Greek crisis has a great impact on all country's economic activities. One of the sectors which mostly have been affected is the construction sector. After the great expand of the general construction industry, due to Olympic Games in 2004 in Athens, the production index of construction (BOG, 2012; 2008) decreased by $-38.8 \%$ for the year 2005, whereas for the next three years recovered by increasing $6.94 \%, 23.4 \%$ and $7.8 \%$ per year respectively. On the contrary, when the Greek crisis began the production index of construction decreased by $-17.6 \%$ for the year 2009, - 29.2\% for 2010 and $-28.8 \%$ for 2011 .

Our analysis focuses on the impact of the Greek economic crisis on the construction sector of the listed firms in Athens Exchange. In particular, we test the crisis

Corresponding Author: Eriotis Nikolaos, National and Kapodistrian University of Athens, Greece 
impact on the profits (or losses, especially after 2008) of these firms by the dynamic use of their assets and liabilities. Based on our recent experience from the Greek economy, during a crisis, simple (or basic) models work better, since they can easily depict the key forces of the economy, which are responsible for the main trend, ignoring marginal factors that play major role in mature economies. We conducted our research using accounting figures and models. Specifically, we use the statistical accounting model, first introduced by Meyer and Kraft (1961).

The structure of this study is a follows; the next section presents the theoretical background of the statistical cost accounting model. In section three we present our data and some necessary descriptive statistics. In section four we present the results of our model estimation and finally, in section five we present our conclusion.

\section{MATERIALS AND METHODS}

The Statistical Cost Accounting Model is designed to assess the costs and revenues generated by the dynamic use of firms' liabilities and assets respectively. The main idea is that firms use their assets in order to produce income, whereas they have to pay the cost of holding debt (in the form of liabilities). Thus, under normal circumstances the assets affect positively and the liabilities negatively the firms' final results.

The Statistical Cost Accounting Model was first applied in the transportation sector by Meyer and Kraft (1961). In their research they estimated a model which expresses the firm's earnings that are affected by the weighted average cost of debt and the weighted average income of assets. Few years later, Hester and Zoellner (1966) applied the statistical cost accounting approach in banking. The empirical analysis of Hester was based on a sample of commercial banks operating in the United States and India. By applying this method, Hester estimated marginal rates of return and costs of bank portfolios. The statistical cost accounting technique revealed profitability differences among banks according to their operating activities and examined the performance of banks over time (Vasiliou, 1998).

This model was first introduced in the Greek economy by Vasiliou (1993) and applied successfully on the Greek Banking sector. It is true that models such as the Statistical Cost Accounting Model are general models, which capture the main forces of the economy. Whereas, in developed economies sophisticated models are necessary to be used and models like the Statistical Cost Accounting Model might be characterized as "too simple"; in economies under crisis, where serious changes occur and the basic economic functions are the only ones that can help the economy to outperform the trough stage, models like the Statistical Cost Accounting Model are appropriate to help us not only to understand the problems of the economy, but to find suitable methods to overcome the shrinking problem.

The Statistical Cost Accounting Model is an empirical model based on the accounting equation as well as on the basic assumptions and principles of accounting. This model uses balance sheet and income statement items in order to interpret differences in companies' returns according to their capital structure by regressing accounting earnings on firms' assets and liabilities. In particular, a variable representing the net results from the income statement is used as a dependent variable, while the balance sheet items are used as earnings explanatory variables. The same logic is applied in our methodology where we explain the performance of the Greek construction companies based on their sources of cost (i.e., liabilities) and income (i.e., assets). In its simplest representation the profit/loss function (1) assumes a multivariate linear form of the assets and liabilities (Vasiliou, 1998):

$$
\begin{aligned}
& Y=f\left(E_{i} I_{j}\right) Y=b_{1} E_{1}=b_{2} E_{2} \\
& +\ldots b_{M} E_{1}+c_{1} I_{1}+c_{2} I_{2}+\ldots+c_{N} I_{N}
\end{aligned}
$$

where, $E_{i}$ the $i_{\text {th }}$ asset element with $i \in[1, M], \Pi_{j}$ the $j_{\text {th }}$ liabilities element with $\mathrm{j} \in[1, \mathrm{~N}]$ and $\mathrm{b}_{\mathrm{i}}, \mathrm{c}_{\mathrm{j}}$ their corresponding coefficients.

Although the assets' values differ from company to company, it is reasonable to claim that the net rate of return on these elements may be about the same regardless of the companies' size. This claim is based upon the view that variations in rates of return on income and individual costs have opposite directions and thus cancel each other out (Hester and Zoellner, 1966). As a result, the net income of a construction company can be expressed as the weighted sum of its various assets and liabilities and the weights are the revenue and cost of each balance sheet item, respectively:

$$
\mathrm{Y}=\sum_{\mathrm{i}=1}^{\mathrm{M}} \mathrm{b}_{\mathrm{i}} \mathrm{E}_{\mathrm{i}}+\sum_{\mathrm{j}=1}^{\mathrm{N}} \mathrm{c}_{\mathrm{i}} \mathrm{II}_{\mathrm{j}}
$$

where, $\mathrm{Y}$ is the net operating income of a construction company (total revenue less total cost), $E_{i}$, the $i$ asset element with $\mathrm{i} \in[1, \mathrm{M}]$ and $\sum_{\mathrm{i}=1}^{\mathrm{M}} \mathrm{E}_{\mathrm{i}}=$ Total Assets, $\Pi_{\mathrm{j}}$ the 
$\mathrm{j}$ liability element with $\mathrm{j} \in[1, \mathrm{~N}]$ and $\sum_{\mathrm{j}=1}^{\mathrm{N}} \mathrm{II}_{\mathrm{i}}=$ Total Liabilities; $b_{i}$ is the net rate of return on asset element Ei and $c_{j}$ the net rate of cost on liability element $\Pi_{j}$. Therefore, each $b_{i}$ sign should be non-negative (i.e., positive or zero) and each $c_{j}$ sign should be non-positive (i.e., zero or negative).

In addition to the above, every company realizes revenues and costs not related to balance sheet items. These revenues may come from rents (machinery, buildings), equity (stocks, dividends), interest on deposits, commissions. The corresponding costs can be derived from advertising campaigns, personnel payroll, electricity, telephone and more. For this reason a constant term is added in function (6) to describe the income/loss which is unrelated to balance sheet items. Again, it is assumed that such revenues and costs remain constant regardless of the company size. Moreover, in order to take into account the random variations between individual companies we insert in function (3) a random deviation, i.e., a random error. So, the statistical approach of the cost accounting model for the construction industry, takes the following form Equation 1:

$$
Y_{k t}=a+\sum_{i=1}^{M} b_{i} E_{i, k, t}+\sum_{j=1}^{N} c_{j} I_{j, k, t}+\varepsilon_{k, t}
$$

Function (4) describes the $\mathrm{k}^{\text {th }}$ company's profit, at time $\mathrm{t}$, in terms of its assets and capital structure at a given point in time, where $\alpha$ is the constant term and $\varepsilon_{\mathrm{k}, \mathrm{t}}$ the random error, for the firm $\mathrm{k}$ at time $\mathrm{t}$. In particular, this equation links the company's profits to the performance of its working capital and the cost of capital. The same function can be used for a cohort of companies taking into account both time series and cross sectional data. To do so, two additional assumptions are made. First, we accept that all construction companies face the same debt costs on various asset and liability items they hold, so that intercompany variations in assets simply reflect different investment preferences. Second, we assume that there is stability over time for the structure of the estimated model. The result of these assumptions is that the coefficients of the independent variables in (4) express the average coefficient of the sample in a given period of time. Thus (4), takes the following form:

$$
Y_{k t}=a+\sum_{i=1}^{M} b_{i} E_{i, k, t}+\sum_{j=1}^{N} c_{j} I_{j, k, t}+\varepsilon_{k, t}
$$

Function (5) utilizes the assumption that the intercept and the rates of return and cost of balance sheet items remain stable, where $\mathrm{k}$ is the construction company with $1 \leq \mathrm{k} \leq \mathrm{K}$ and $\mathrm{t}$ is the time.
The econometric method used to estimate the parameters of the model is the method of least squares, which is usually applied to a cross sectional sample of businesses. The first fundamental issue to be identified is the possible existence of heteroscedasticity (This refers to a violation of the assumption that the error term observations are based on identical distributions and therefore the error term has constant variance. The errors resulting from the estimation of the model reflect the influence of the parameters on the dependent variable and probably they contain information which was not taken into account due to potential omission of explanatory variables. Thus, the variance of the errors can vary systematically with the explanatory variables or vary over time, especially with cross sectional samples that are typically used in the statistical cost accounting models). Most of the statistical cost accounting studies claim that the variance of the error term is linked to an independent variable such as the company size. As a result, most researchers in order to eliminate the problem of heteroscedasticity suggest the removal of the company size effect by dividing each element of function (5) by the total assets for a given period of time (Vasiliou, 1998). Thereby, the resulting function is the following, where $\Sigma \mathrm{E}_{\mathrm{k}, \mathrm{t}}$ is the total asset of company $\mathrm{k}$ at time $\mathrm{t}$ :

$$
\frac{\mathrm{Y}_{\mathrm{kt}}}{\sum \mathrm{E}_{\mathrm{k}, \mathrm{t}}}=\frac{\mathrm{a}}{\sum \mathrm{E}_{\mathrm{k}, \mathrm{t}}}+\sum_{\mathrm{i}=1}^{\mathrm{M}} \mathrm{b}_{\mathrm{i}} \frac{\mathrm{E}_{\mathrm{i}, \mathrm{k}, \mathrm{t}}}{\sum \mathrm{E}_{\mathrm{k}, \mathrm{t}}}+\sum_{\mathrm{j}=1}^{\mathrm{N}} \mathrm{c}_{\mathrm{j}} \frac{\mathrm{II}_{\mathrm{j}, \mathrm{k}, \mathrm{t}}}{\sum \mathrm{E}_{\mathrm{k}, \mathrm{t}}}+\frac{\varepsilon_{\mathrm{k}, \mathrm{t}}}{\sum \mathrm{E}_{\mathrm{k}, \mathrm{t}}}
$$

Beyond heteroscedasticity, another equally significant issue is that of collinearity. The transformed function, resulting after the division, has an exact linear relationship among the explanatory variables and thus the estimated variances of the estimators are infinite. This violates the constant variance assumption used in the model. In particular, in the statistical cost accounting model there is a perfectly linear relationship among the explanatory variables derived from the fact that the sum of assets equals the sum of liabilities and equity of the entity. That is, Assets = Liabilities + Shareholder's Equity.

The equation for assets and liabilities items is Equation 2 and 3:

$\sum_{\mathrm{i}=1}^{\mathrm{M}} \mathrm{E}_{\mathrm{i}} \sum_{\mathrm{j}=1}^{\mathrm{N}} \mathrm{II}_{\mathrm{j}}$

While the equation for assets and liability proportions related to the working capital of a construction company is: 
$\sum_{i=1}^{\mathrm{M}=1} \frac{\mathrm{E}_{\mathrm{i}}}{\sum \mathrm{E}} \sum_{\mathrm{j}=1}^{\mathrm{N}} \frac{\mathrm{II}_{\mathrm{j}}}{\sum \mathrm{E}}$

The perfect collinearity in function can be eliminated by excluding an asset and/or a liability item and adding a constant term, which represents the effects of these items (Vasiliou, 1998). The result of these transformations is a function which contains no independent variables linearly related to each other. So, the new function has eliminated the collinearity problem. Based on related researches, we correct the collinearity problem by erasing the share holders' equity, considering that the cost of shareholders' equity is represented by the dependent variable, i.e., the results of the firm which have already been scaled by the total assets of the firm. By doing this, the final model estimates the impact on shareholders' return, expressed as return on total assets, from the firm's financing and investing policy.

Our sample is consisted of a panel of data covering the last seven years of the Greek firms listed in the Athens Exchange. We consider a big advantage in our estimation process the combined use of time series and cross section data, since it gives us the opportunity to examine differences among companies within our sample (Our analysis is based on Green (2002)). In other words, panel data takes into account the particular cross sectional characteristics of each group of items or each item individually.

In this study we are dealing with published accounts of construction companies and even though all companies are listed in the same sector each one has distinct investment scheme and capital structure. As a result, the yields and costs of each company's assets and liabilities are affected according to the firm's specific characteristics. Using panel data models, we try to isolate the specific characteristics of each company and estimate the average total return of each asset item and the average total cost of each liability item. Thus, we first estimate our model, under the hypothesis that there are no firm's individual characteristics, using the following model specification, where we include a dummy variable that captures the affection, if there is any, of the Greek economic crises on the construction industry (model 1):

$$
\begin{aligned}
& Y_{i, t}=a_{0}+a_{1} x_{1, i, t}+a_{2} x_{2, i, t}+a_{3} x_{3, i, t}+a_{4} x_{4, i, t} \\
& +a_{5} x_{5, i, t}+a_{6} x_{6, i, t}+a_{7} x_{7, i, t}+a_{8} x_{8, i, t}+a_{9} x_{9, i, t}+e_{i, t}
\end{aligned}
$$

where, $\mathrm{i}$ is the firm, $\mathrm{t}$ is the time, $\mathrm{Y}_{\mathrm{i}, \mathrm{t}}$ is the $\frac{\text { Net Revenues }}{\text { Total Assets }_{\mathrm{i}, \mathrm{t}}}, \mathrm{a}_{0}$ is the constant term, $\mathrm{X}_{1, \mathrm{i}, \mathrm{t}}$ is the $\frac{\text { Total Fixed Assets }}{\text { Total Assets }_{\mathrm{i}, \mathrm{t}}}, \mathrm{X}_{2, \mathrm{i}, \mathrm{t}}$ is the $\frac{\text { Iventory }}{\text { Total Assets }_{\mathrm{i}, \mathrm{t}}}, \mathrm{X}_{3, \mathrm{i}, \mathrm{t}}$ is the $\frac{\text { Receivables }}{\text { Total Assets }_{\mathrm{i}, \mathrm{t}}}, \mathrm{X}_{4, \mathrm{i}, \mathrm{t}}$ is the $\frac{\text { Cash and Cash Equialents }}{\text { Total Assets }_{\mathrm{i}, \mathrm{t}}}, \mathrm{X}_{5, \mathrm{i}, \mathrm{t}}$ is the $\frac{\text { Long Term Liabilities }}{\text { Total Liabilities }_{\mathrm{i}, \mathrm{t}}}, \mathrm{X}_{6, \mathrm{i}, \mathrm{t}}$ is the $\frac{\text { Provision }}{\text { Total Liabilities }_{\mathrm{i}, \mathrm{t}}} \mathrm{X}_{7, \mathrm{i}, \mathrm{t}}$ is the $\frac{\text { Short Term Liabilities banks }}{\text { Total Liabilities }_{\mathrm{i}, \mathrm{t}}}, \mathrm{X}_{8, \mathrm{i}, \mathrm{t}}$ is the $\frac{\text { Other Short Term Liabilities }}{\text { Total Liabilities }_{\mathrm{i}, \mathrm{t}}}, \mathrm{X}_{9, \mathrm{i}, \mathrm{t}}$ is the dummy variable and $\mathrm{e}_{\mathrm{i}, \mathrm{t}}$ is the error term. Where, the dummy variable takes the value of 0 before the economic crises and 1 after it.

Additionally, we estimate the model under the fixed effects hypothesis (We also tried the random effects model and its hypothesis, which seems not to be the appropriate one for our model and data estimation), where we measure differences in intercepts for each firm. The approach is also called "Least Squares Dummy Variable" method because the differences are calculated using a separate dummy variable for each firm. The fixed effects model represents the observed quantities in terms of explanatory variables that are treated as if the quantities were non-random. This is basically an OLS model with dummy variables to control group or individual differences, assuming constant coefficients for independent variables and constant variance across groups or individuals. The specification of the model differs slightly in the last case, with $\mathrm{a}_{0}$ the constant term representing the general constant estimation and the $a_{0, i}$ term the individual's firm adjustment to the general constant term (model 2):

$$
\begin{aligned}
& Y_{i, t}=a_{0}+a_{0, i}^{\prime}+a_{1} x_{1, i, t}+a_{2} x_{2, i, t}+a_{3} x_{3, i, t}+a_{4} x_{4, i, t} \\
& +a_{5} x_{5, i, t}+a_{6} x_{6, i, t}+a_{7} x_{7, i, t}+a_{8} x_{8, i, t}+a_{9} x_{9, i, t}+e_{i, t}
\end{aligned}
$$

\section{THE INDUSTRY, OUT DATA AND SOME BASIC DESCRIPTIVE STATISTICS}

\subsection{The Industry}

It is true that the growth of a company depends on the economic environment, where the firm produces and sells its products. Thus, the construction industry growth 
is directly related to the domestic economic prospects. It is intuitive that the existence of a healthy economy with good infrastructure increases productivity and reduces production costs for each production sector. In Greece, the construction sector from 1994 up to 2005, recorded fast increasing rates with the highest point just before 2004 due to the Athens 2004 Olympic Games. After the last quarter of 2006 the Greek construction sector started to slow down and finally, by the end of 2008 the construction activity decreased sharply.

The current Greek economic environment can be characterized as the riskiest one in the euro zone, in which the Greek construction companies face intense competition that force them to restructure, merge or form strategic alliances. According to the (FEIR, 2011), the successful absorption of EU funds, the development of private construction activity and the progressive realization of public and private collaborations, are the main factors that expect to establish the future development for the Greek construction industry. According to its findings, there are two crucial types of problems related to the Greek construction industry. The first type of problem refers to the institutional framework concerning the undertaking of public and private projects. The most important problems of this category are the complexity and over-regulation, the lack of National Land Planning and the bureaucratic delays of the National Land Registry Offices. The second type of problem includes problems associated with the prevailing competitive practices in the market, such as unfair competition and biased public projects biddings. Solutions proposed by FEIR refer to actions which need to be made by both the state and the private sector.

\subsection{The Sample}

The Greek construction industry was widely developed in the period 2000-2004, while from 2008 there is a continuous steep decline of building activity with new lower levels recorded constantly. The sample of companies includes the construction businesses which operate in the Greek market and traded in the Athens Stock Exchange between 2005 and 2011. The total number of firms used in our empirical analysis is fifteen, since we had to exclude two firms that stopped trading at Athens Exchange in 2008.

The main reason using the firms listed on the Athens Exchange is that they operate under specific standards and regulations, ensuring the consistency of the recorded and used data. Additionally, all the firms listed on Athens Exchange publish their accounting records according to IAS providing a uniform information presentation for our sample. Our sample data used for our model estimation are based on the public financial statement of the construction section of the firms listed on the Athens Exchange. These data have been organized as follows: the assets presented on the balance sheet are separated to four categories, the fixed assets (including tangible and intangible assets), the inventories, the accounts receivables and the cash and cash equivalents. The liabilities of the firm are categorized into four categories too, including the long term liabilities, the provisions of the long term liabilities, the financial short term liabilities and the other short term liabilities. Finally, the net profit or losses of the firms are used to create the dependent variable, the profit and loss statements. The yearly average values of the above accounts for the sampled firms in accordance with the shareholders' equity are expressed as the percentage of the total assets and are presented in the following Table 1. Based on the results presented in Table 1 there is an obvious decrease in the participation of current assets of the total assets of the firm, due to the reduction of the total capital used by the firm. In an environment where the rate of construction is falling rapidly, there are no investments and thus no inventories and accounts receivables. On the contrary there is an increase of the participation of the fixed assets and the cash equivalent accounts on the total capital of the firm. This happens since the fixed assets remaining on the firms' possession, are waiting for the recovery and the cash accounts are used to maintain the firms' survival in the tough Greek economic environment. As far as the liabilities are concerned, there is a decrease in the long term debt, since there is a reduction on the constructions' firms financing, an increase to provisions due to the financial crisis and an increase to short term debt to banks which now try to collect their money from the firms. Finally, there is a decrease in the shareholders' equity due to the negative results of the firms.

\section{RESULTS AND DISCUSION}

Our empirical findings proved to be very interesting since both models are statistically significant, the estimated coefficients are close to the cost accounting model hypothesis and the dummy variable is also statistically significant. The estimated $\mathrm{R}^{2}$ adj highly denote that the $57 \%$ and the $58 \%$ of the variation of our dependent variable can be explained by model 1 and model 2 respectively. 
Table 1. Statistics

\begin{tabular}{|c|c|c|c|c|c|c|c|c|c|c|}
\hline Year & $\begin{array}{l}\text { Total } \\
\text { fixed } \\
\text { assets }(\%)\end{array}$ & $\begin{array}{l}\text { Inventories } \\
(\%)\end{array}$ & $\begin{array}{l}\text { Accounts } \\
\text { receivables } \\
(\%)\end{array}$ & $\begin{array}{l}\text { Cash and } \\
\text { cash } \\
\text { equivalents }(\%)\end{array}$ & $\begin{array}{l}\text { Long tern } \\
\text { liabilities } \\
(\%)\end{array}$ & $\begin{array}{l}\text { Provision } \\
(\%)\end{array}$ & $\begin{array}{l}\text { Short tern } \\
\text { liabilities to } \\
\text { banks (\%) }\end{array}$ & $\begin{array}{l}\text { Other } \\
\text { short term } \\
\text { liabilities (\%) }\end{array}$ & $\begin{array}{l}\text { Shareholders } \\
\text { Equity }(\%)\end{array}$ & $\begin{array}{l}\text { Profit/ } \\
\text { Losses } \\
(\%)\end{array}$ \\
\hline 2005 & 48.98 & 5.87 & 22.46 & 22.69 & 10.44 & 0.04 & 15.73 & 20.77 & 53.02 & 0.93 \\
\hline 2006 & 50.34 & 4.78 & 22.55 & 22.33 & 14.05 & 0.22 & 12.57 & 20.29 & 52.87 & 1.24 \\
\hline 2007 & 52.28 & 4.11 & 21.11 & 22.50 & 13.95 & 2.31 & 11.51 & 20.07 & 52.16 & 0.24 \\
\hline 2008 & 52.92 & 3.16 & 21.46 & 22.46 & 11.07 & 7.34 & 12.00 & 21.04 & 48.55 & -9.27 \\
\hline 2009 & 51.89 & 3.22 & 21.19 & 23.70 & 9.68 & 6.60 & 15.48 & 17.96 & 50.28 & -1.90 \\
\hline 2010 & 54.81 & 2.60 & 19.00 & 23.59 & 7.18 & 6.17 & 17.11 & 19.87 & 49.67 & -5.20 \\
\hline 2011 & 56.95 & 2.70 & 17.79 & 22.56 & 7.60 & 4.46 & 18.49 & 23.34 & 46.11 & -7.95 \\
\hline
\end{tabular}

Table 2. Results

\begin{tabular}{|c|c|c|c|c|c|c|}
\hline \multirow[b]{2}{*}{ Coeff. } & \multicolumn{3}{|c|}{ Model 1} & \multicolumn{3}{|c|}{ Model 2} \\
\hline & Value & T-stat. & Prob. & Value & T-stat. & Prob. \\
\hline $\mathrm{a}_{0}$ & 0.075 & 6.154 & 0.000 & 0.067 & 1.943 & 0.055 \\
\hline$a_{0, i}$ & - & & & See Tal & & \\
\hline$a_{1}$ & -0.039 & -2.016 & 0.046 & -0.033 & -3.1031 & 0.003 \\
\hline$a_{2}$ & 0.281 & 3.671 & 0.000 & 0.372 & 2.9020 & 0.005 \\
\hline$a_{3}$ & 0.106 & 4.250 & 0.000 & 0.163 & 6.7550 & 0.000 \\
\hline$a_{4}$ & 0.054 & 1.443 & 0.152 & 0.055 & 1.6020 & 0.113 \\
\hline$a_{5}$ & -0.079 & -3.163 & 0.002 & -0.147 & -3.5960 & 0.001 \\
\hline$a_{6}$ & -0.217 & -7.085 & 0.000 & -0.234 & -11.0100 & 0.000 \\
\hline$a_{7}$ & -0.260 & -2.089 & 0.039 & -0.231 & -2.6260 & 0.010 \\
\hline$a_{8}$ & -0.268 & -4.056 & 0.000 & -0.352 & -2.7800 & 0.007 \\
\hline$a_{9}$ & -0.029 & -3.414 & 0.000 & -0.018 & -2.1650 & 0.033 \\
\hline $\mathrm{R}^{2}$ & 0.605 & & & 0.675 & & \\
\hline $\mathrm{R}^{2}$-adj. & 0.570 & & & 0.581 & & \\
\hline F-stat. & 17.370 & Prob. & 0.000 & 7.157 & Prob. & 0.000 \\
\hline D.W. & 1.392 & & & 1.774 & & \\
\hline
\end{tabular}

The estimated constant term $\mathrm{a}_{0}$ is statistically significant for the first model and hardly rejected by the second model, with probability just above the $5 \%$ $(5.5 \%)$. Its value (in both models) is positive and represents the average return of a firm based on the sector's dynamics. All variables, representing the long and short term liabilities, are negative and statistically significant, for both models, representing the average cost of using debt in the form of $\mathrm{x}_{5}, \mathrm{x}_{6}, \mathrm{x}_{7}$ and $\mathrm{x}_{8}$ variables as defined in section two. The highest cost of liabilities holdings is the short term liabilities to non financial creditors ( $\mathrm{x}_{8}$ variable) and the lowest cost is the long term liabilities ( $\mathrm{x}_{5}$ variable).

The assets variables estimated in both models represent the returns of the average firm from its investments. All asset variables, with exception the cash and cash equivalent items, are statistically significant. The non significance of the cash and cash equivalent was expected since there is no direct return from holding cash items. Holding cash increases the firms' liquidity and provides it with working capital, thus it increases the investment perspectives of the firms having an indirect and long run impact on the firms' returns. The asset item with the highest estimated return is the firms' inventories and the second ranked item is the accounts receivables; this result is consistent to the financial and accounting theory, since the former is the main source of income and the later represents the interest earned from the credit sales. As far as the fixed assets coefficient is concerned, our findings provided us with opposite to the theory sign, since they have negative mark for both models estimations. Even though this is a bizarre finding, it is consistent with the theory that the cost statistical model is based on. As we saw earlier on, in section one, Greek economy faces one of the most intense recessions in its history with tremendous impact on its all economic activities, including the construction sector. Thus, the negative sign estimated in both models reflects the fact that the fixed assets of the construction companies in Greece cost more than what they actually produce, something which is true since the fixed assets of these firms are underemployed. Finally, crisis dummy variable has a statistically significant negative sign denoting the negative effect of the Greek economic crisis on the average returns. The following Table 2, presents a summary of our empirical findings. 
Table 3. Results

\begin{tabular}{lrlrlr}
\hline Firm i & \multicolumn{1}{c}{$\mathrm{a}_{0, \mathrm{i}}^{\prime}$} & Firm i & $\mathrm{a}_{0, \mathrm{i}}^{\prime}$ & Firm i & \multicolumn{1}{c}{$\mathrm{a}_{0, \mathrm{i}}^{\prime}$} \\
\hline $\mathrm{A}$ & 0.0059 & $\mathrm{~F}$ & 0.0066 & $\mathrm{~K}$ & 0.0308 \\
$\mathrm{~B}$ & -0.0058 & $\mathrm{G}$ & 0.0103 & $\mathrm{~L}$ & -0.0030 \\
$\mathrm{C}$ & -0.0096 & $\mathrm{H}$ & 0.0276 & $\mathrm{M}$ & 0.0177 \\
$\mathrm{D}$ & 0.0148 & $\mathrm{I}$ & -0.1561 & $\mathrm{~N}$ & 0.1306 \\
$\mathrm{E}$ & -0.0012 & $\mathrm{~J}$ & 0.0236 & $\mathrm{O}$ & -0.0450 \\
\hline
\end{tabular}

\section{CONCLUSION}

In this study, the statistical cost accounting model has been used to capture the impact of the Greek economic crisis on the Greek construction sector. The evidence from our analysis suggests that the construction sector has been affected by the Greek crisis since there is a great decrease of the construction activities. According to our findings the theory supports the Statistical Cost Accounting Model and reveals that there is a negative impact on the earnings of the construction firms that comes from the underemployment of their fixed assets, which, under the Greek crisis, cost more than what they actually produce. Additionally, we found that the cash and cash equivalent items do not actually help our sample firms to produce profit and the most expensive item of the balance sheet is the non financial short term liabilities.

Our analysis focuses in one sector of the Greek economic activity and reveals the main negative forces of the construction sector. The truth is that Greek economy suffers not only on its macroeconomic level but on the microeconomic as well, where there are different sectors facing problems due to different causes. The Statistical Cost Accounting Model helped us to detect some of them in the construction sector and it may be useful to be tested in other sectors of the economy as well.

\section{REFERENCES}

BOG, 2008. Bulleting of Conjuctural Indicators. Bank of Greece, Athens, Greece.

BOG, 2012. Bulleting of Conjuctural Indicators. Bank of Greece, Athens, Greece.

De Grauwe, P., 2010. The start of a systemic crisis of the eurozone? Policy Analysis and Commentary from Leading Economists.

FEIR, 2011. Greek Economy, Quarterly Bulletin for the Greek Economy. Foundation for Economic and Industrial Research.

Green, W., 2002. Econometric Analysis. 5th Edn., Prentice-Hall, New Jersey.

Hardouvelis, G.A., 2011, The Greek and European crisis and the new architecture of the eurozone. Economy and the Markets Bulletin, EFG Eurobank.

Hester, D.D. and J.F. Zoellner, 1966. The relation between bank portfolios and earnings: An econometric analysis. Rev. Econom. Stat., 48: 372386.

Kouretas, G.P. and P. Vlamis, 2010. The greek crisis: Causes and implications. Panoeconomicus, 4: 391404.

Meyer, J.R. and G. Kraft, 1961. The evaluation of statistical costing techniques as applied in the transportation industry. Am. Econo. Rev., 51: 313-334.

Vasiliou, D., 1993. A statistical cost analysis of the profitability differences of greek commercial banls. Quaderni di Economia e Finenza, 3: 91-101.

Vasiliou, D., 1998. A Bird's eye view of the statistical accounting model in banking. Studies Regional Urban Plann., 6: 103-117. 